\title{
Optimized Generation Costs Using Modified Particle Swarm Optimization Version
}

\author{
ADEL ALI ABOU EL-ELA \\ Electrical Engineering Department \\ Minoufiya University \\ Shebin El Kom Minoufiya \\ EGYPT \\ draaa50@hotmail.com \\ RAGAB ABDEL-AZIZ EL-SEHIEMY \\ Marine Constructions Department \\ The Arab Contractor (Osman Ahmed Osman \& Co.,) \\ The $10^{\text {th }}$ of Ramadan City \\ EGYPT \\ elsehiemy@yahoo.com
}

\begin{abstract}
This paper proposes Modified Sensitivity Factors (MSF) for computing the transmission power flows in terms of power generation outputs at different emergency events. The proposed MSF are capable for obtaining higher quality solutions for different power system problems. A modified particle swarm optimization (MPSO) version is proposed to solve the power dispatch problem. Comparison studies which are based on the optimal generation costs are performed to show the superiority of the proposed MSF compared to the existed sensitivity factors. In the competitive environment, the use of the proposed sensitivity factors leads to fair allocation of user responsibilities in recovery problems such as loss allocation and transmission usage allocation problems.
\end{abstract}

Key-Words: - Deregulated power systems, particle swarm optimization technique, production cost minimization, sensitivity analysis.

\section{Introduction}

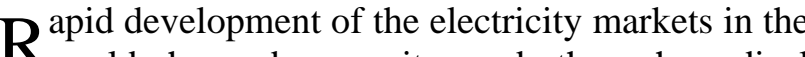
$\mathbf{R}_{\text {world have been witnessed through radical }}$ changes due to deregulation / privatization process. The traditional vertically integrated systems were divided into individual companies to provide a suitable reduction level of consumer prices by means of competition. The competition in electricity is constrained by the available transfer capabilities and the level of transmission congestion in a market.

A variety of applications in both planning and operation require repetitive computations of transmission power flows and transmission power losses. Sensitivity factors were presented as the generalized generation distribution factors (GGDF) for obtaining the power flows in transmission lines in terms of the injected power generations [1]. Topological generation and load distribution factors were presented in [2]. A modification of the topological generation and load distribution factors for power flows and transmission power losses was presented in [3].
Reference [4] presented three main market models namely centralized markets, standard auction and spot pricing (hybrid markets). Reference [4] focused on the inclusion of proper security constraints in the optimal power flow (OPF) market model. Reference [5] considered the impact of transmission constraints on security constrained generation scheduling problem in the competitive market.

Different electricity market models were presented to maximize the market profit and minimizing the production costs [6]. A probabilistic transmission planning model was evaluated the expansion and reinforcement of transmission system using an adequacy linear programming model in the liberalized electricity markets [7].

Modern heuristics optimization techniques were considered as practical tools for non-linear optimization problems [8-21]. The Particle Swarm Optimization (PSO) technique was invented by Kennedy and Eberhart in 1995. The PSO is a relatively recent heuristic search method whose mechanics are inspired by the swarming or 
collaborative behaviour of biological populations. The PSO technique is considered as a realistic and powerful solution scheme for solving continuous non-linear optimization problems.

Recently, PSO has been successively applied to various fields of power system optimization problems such as for economic dispatch problem considering generation constraint [8], for minimizing the non-smooth cost function of economic dispatch problem [9], scheduling the generation outputs considering lagrangian relaxation method [10], reactive power and voltage control [11-13], optimal design of power system stabilizer [14], optimal power flow [15], state estimation [16], and for unit commitment problem [17]. The multiobjective generation dispatch using PSO with multiple fuel option were presented in [18] while, in [19], the multi-objective generation dispatch using PSO was presented for electricity markets. Reference [20] presented a procedure using PSO for obtaining the optimal design of a neuro-sliding mode controller for the transient stability enhancement of multimachine power systems with UPFC. In [21], the application of PSO technique to obtain the optimal transmission loss allocation levels at market individuals (generation and demand) was obtained.

In this paper, the main contribution is to propose new sensitivity factors for computing the transmission power flows in terms of power generation outputs considering emergency events. Added to that, a modified version of PSO technique is proposed to minimize the power generation costs considering the suggested sensitivity factors.

\section{Problem Formulation}

The generation dispatch formulation can be stated as [6]:

$$
\text { Min } C=\sum_{i=1}^{N G}\left(C_{i}\left(P G_{i}\right)\right)
$$

The generation cost function is described by a quadratic function as:

$$
C_{i}\left(P G_{i}\right)=a_{i} P G_{i}^{2}+b_{i} P G_{i}+c_{i}, i, 2, \ldots . ., N G
$$

Where,

C The total power generation costs of each generator at bus $\mathrm{i}$ cost $\left(C_{i}\left(P G_{i}\right)\right)$.

$P G_{i} \quad$ Is the generation company output.

$N G$ Is the number of generation companies.

$a_{i}, b_{i}$ and $c_{i}$ are the generation cost coefficients
The objective function in (1) is subjected to the set of system operating constraints including the system power flow equations and line flow limits.

- Power balance constraint.

The power balance constraint can be written as:

$\sum_{i=1}^{N G} P G_{i}=\sum_{j=1}^{N D} P D_{j}$

Where, the total power generated all GENCOs should be equal to the total system demand includes both of consumer power demands and transmission losses. $N D$ is the number of consumer companies.

\section{- Congestion constraint}

The power flow in each transmission line $\mathrm{k}\left(P F_{k}\right)$ must be less than the maximum bending limit of this transmission network $\left(P F_{k}^{\max }\right)$.

$$
\left|P F_{k}\right| \leq P F_{k}^{\max }, \quad k=1,2, \ldots, N L,
$$

Where, NL is the total number of transmission lines.

- $\quad$ Capacity (physical) constraints

The minimum and maximum generation limitations are expressed as:

$$
P G_{i}^{\min } \leq P G_{i} \leq P G_{i}^{\max }, i=1,2, \ldots N G
$$

\section{Sensitivity Factors}

\section{A. General Generation Distribution Factors (GGDF)}

The GGDF coefficients were used to compute the power flow in transmission line $\mathrm{m}$ as a function of power generation outputs as [1]:

$$
\begin{aligned}
& P F_{m}=\sum_{i=1}^{N G}\left(D_{m, i} \cdot P G_{i}\right) \\
& D_{m, i}=D_{m, r}+A_{m, j} \\
& D_{m, r}=\left(P F_{m}^{0}-\sum_{\substack{i=1 \\
i \neq r}}^{N G} A_{m, i} P G_{i}\right) / \sum_{i=1}^{N G} P G_{i}
\end{aligned}
$$

Where:

$D_{m, i} \quad$ is the GGDF between line $m$ and bus $i$,

$D_{m, r} \quad$ is the GGDF between line $m$ and slack bus $r$.

$A_{m, j} \quad$ is the generation shift distribution factors

$P F_{m}^{0} \quad$ is the initial power flow of line $m$.

\section{B. Proposed Modified Sensitivity Factors}

The proposed MSF are dependent on the actual power system measurements for initial power flows in transmission lines and the corresponding power generation outputs which can be written as:

$$
P F=D_{m} . P G
$$


$\mathrm{PF}=\left[\mathrm{PF}_{1} \mathrm{PF}_{2} \mathrm{PF}_{3} \ldots . . ., \mathrm{PF}_{\mathrm{k}}, \ldots . ., \mathrm{PF}_{\mathrm{NL}}\right], \mathrm{k}=1,2, \ldots . ., \mathrm{NL}$

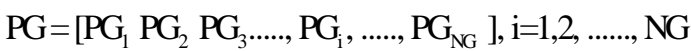

Where, $\mathrm{D}_{\mathrm{m}}$ is the proposed MSF.

The initial power flows in terms of initial power generation can be written as:

$P F^{0}=D_{m} \cdot P G^{0}$

By multiplying the both sides of Equation (10) by $\left(P G^{0}\right)^{t}$, it can be get:

$P F^{0} \cdot\left(P G^{0}\right)^{t}=D_{m} \cdot\left(P G^{0}\right) \cdot\left(P G^{0}\right)^{t}$

Also, by multiplying the both sides of Equation (11) by the inverse of the matrix $\left(\left(P G^{0}\right) \cdot\left(P G^{0}\right)^{t}\right)$ it can be obtained:

$$
\begin{aligned}
& P F^{0} \cdot\left(P G^{0}\right)^{t} \cdot\left(\left(P G^{0}\right) \cdot\left(P G^{0}\right)^{t}\right)^{(-1)}= \\
& D_{m} \cdot\left(P G^{0}\right) \cdot\left(P G^{0}\right)^{t} \cdot\left(\left(P G^{0}\right) \cdot\left(P G^{0}\right)^{t}\right)^{(-1)}=D_{m} \\
& \therefore D_{m}=P F^{0} \cdot\left(P G^{0}\right)^{t} \cdot\left(\left(P G^{0}\right) \cdot\left(P G^{0}\right)^{t}\right)^{(-1)}
\end{aligned}
$$

Equation (13) presents the final formula of the proposed MSF which are dependent on the actual initial measurements of the power flows in transmission lines and the power generations. It is cleared that no approximations in the bus voltages or the line resistances as the effects of circuit resistances are fully considered.

The power flow $\left(P F_{k}\right)$ in (4) can be written as:

$$
\begin{aligned}
& P F_{k}=\sum_{i=1}^{N G}\left(\left(D_{m}\right)_{k, i} \cdot P G_{i}\right) \\
& \left(D_{m}\right)_{k, i}=P F_{k}^{0} \cdot\left(P G_{k, i}^{0}\right)^{t} \cdot\left(\left(P G_{k, i}^{0}\right) \cdot\left(P G_{k, i}^{0}\right)^{t}\right)^{(-1)}
\end{aligned}
$$

Where,

$\left(D_{m}\right)_{k, i} \quad$ is the MSF between line $\mathrm{k}$ and generation $\mathrm{i}$. $\left(P G_{k, i}^{0}\right)^{t} \quad$ is the transpose of power generation $P G_{k, i}^{0}$.

\section{Modified Particle Swarm Optimization Version}

In this paper, a modified PSO model based on the collected information of self and group experience with respect to the current agent position is proposed for solving the security constrained power generation dispatch problem. The conventional PSO technique presented in [8-10] was considered as:

$$
\begin{aligned}
\Delta P G_{i, k}=W . \Delta P G_{i, k} & +C_{1} R_{1}\left(P G_{i, \mathrm{k}}^{\text {Pbest }}-P G_{i, k}\right) \\
& +C_{2} R_{2}\left(P G_{i, \mathrm{k}}^{\text {Gbest }}-P G_{i, k}\right)
\end{aligned}
$$

$$
\begin{aligned}
& P G_{i, k+1}=P G_{i, k}+\Delta P G_{i, k} \\
& W=\frac{W^{\max }-\left(W^{\max }-W^{\min }\right)}{\text { Iter max }} \text { iter }
\end{aligned}
$$

Where, the large number of inertia factor (W) leads to more global solution. The coefficients $\mathrm{C}_{1}$ and $\mathrm{C}_{2}$ are the learning factors which PSO technique optimizes different objective functions on the basis of personal and group experiences and each agent tries to modify its position based on the follows:

- Both of agent position and transition information as each agent transition $\left(\triangle P G_{k, i}\right)$ is constrained by the minimum and maximum agent transitions, at iteration $\mathrm{k}$ for individual $\mathrm{k}$, as:

$$
T_{k, i}^{\min } \leq \Delta P G_{k, i} \leq T_{k, i}^{\max }
$$

The minimum and maximum agent transitions can be obtained from:

$T_{k, i}^{\max }=k_{m}\left(P G_{k, i}^{\max }-P G_{k, i}^{\min }\right)$,

$T_{k, i}^{\min }=-k_{m}\left(P G_{k, i}^{\max }-P G_{k, i}^{\min }\right)$

- Reduction of searching space by applying the limit reduction strategy for generation limits. This constraint reduces the space of searching between the minimum and maximum individual limits to new space searching space. This action helps the agent in the early convergence of the optimality problem. The maximum and minimum individual limits can be updated from:

$$
\left\{\begin{array}{c}
\left(P G_{k, i}^{\max }=P G_{k, i}^{\max }-\delta\left(P G_{k, i}^{\max }-P G_{k, i}^{\text {Pbest }}\right)\right. \\
P G_{k, i}^{\min }=P G_{k, i}^{\min }+\delta\left(P G_{k, i}^{\text {Gbest }}-P G_{k, i}^{\min }\right)
\end{array}\right.
$$

Equations (16) through (21) are used for updating the current, personal best and global positions of Nind individuals. The need to adjust the learning coefficient leads us to modify the conventional PSO to modified PSO (MPSO) model. The MPSO reduces the conventional PSO to a single experience term. The proposed updating formula of the MPSO can be written as:

$$
\begin{aligned}
\Delta P G_{i, k} & =W \cdot \Delta P G_{i, k}+ \\
& +C_{m}\left(P G_{i, k} / P G_{i, \mathrm{k}}^{\text {Geet }}\right)\left(\left(P G_{i, \mathrm{k}}^{\text {Gest }}+P G_{i, \mathrm{k}}^{\text {Plest }}-2 P G_{i, k}\right)\right.
\end{aligned}
$$

Where,

$P G_{k, i} \quad$ is the power of generation i at iteration $\mathrm{k}$.

$\Delta P G_{k, i}$ is the change in power generation $i$ at iteration $\mathrm{k}$.

$P G_{i, k+1}$ is the power generation $\mathrm{i}$ at iteration $\mathrm{k}+1$.

$P G_{k, i}^{\text {Pbest }} \quad$ is the personal best of power generation i,

$P G_{k, i}^{\text {Gbest }}$ is the global best of power generation i at 
iteration $\mathrm{k}$.

\begin{tabular}{|c|c|}
\hline$P G_{k, i}^{\max }$ & um limit of generation \\
\hline$P G_{k, i}^{\min }$ & $\begin{array}{l}\text { the minimum limit of generation } \mathrm{i} \text { at } \\
\text { eration } \mathrm{k} \text {. }\end{array}$ \\
\hline$T_{k, i}^{\max }$ & $\begin{array}{l}\text { is the maximum transition of generation } \mathrm{i} \\
\text { at iteration } \mathrm{k} \text {. }\end{array}$ \\
\hline$T_{k, i}^{\min }$ & $\begin{array}{l}\text { is the minimum transition of generation } \mathrm{i} \\
\text { at iteration } \mathrm{k} \text {. }\end{array}$ \\
\hline$k_{m}$ & is the transition factor. \\
\hline$\delta$ & is the reduction space factor. \\
\hline$W$ & tor of updating formula. \\
\hline$W^{\min }$ & is the minimum inertia factor \\
\hline$W^{\max }$ & is the maximum inertia factors. \\
\hline Iter & is th \\
\hline Iter max & is the maximum iteration number. \\
\hline $\mathrm{C}_{1}$ & $\begin{array}{l}\text { is the learning coefficient for self } \\
\text { experience, }\end{array}$ \\
\hline $\mathrm{C}_{2}$ & $\begin{array}{l}\text { is the learning coefficient for the group } \\
\text { experience }\end{array}$ \\
\hline $\mathrm{C}_{\mathrm{m}}$ & $\begin{array}{l}\text { is the learning coefficient for the modified } \\
\text { experience }\end{array}$ \\
\hline $\mathrm{R}_{1}, \mathrm{R}_{2}$ & are random values in the range $(0,1)$. \\
\hline Nind & e No. of individuals of PSO ve \\
\hline
\end{tabular}

\section{Applications}

\section{A. Test Systems}

The 5-bus [22], and 57-bus test systems [23] are used for an extensive study to the proposed modified techniques. The power flow calculations are performed using MATPOWER 3.0 [23]. The PSO parameters are: $k_{m}=0.1, \quad \delta=0.15-0.45$, $0.3 \leq W \leq 0.7$, Iter $\max =100, C_{1}=C_{2}=2, C_{m}=1.4, \mathrm{~N}$ ind $=50$

\section{B. Results and Comments}

Table 1 shows a comparison between the GGDF [1] and the proposed MSF applied on 5-bus test system. The proposed MSF reallocate the responsibilities of the individual generation in the power flow of transmission lines. For example, the power flow in transmission line No. 1 is affected by $64.03 \%$ of $G_{1}$ only. The power flow components due to generations $G_{2}$ and $G_{5}$ are in the opposite direction of that component due to $G_{1}$ in this line. Only line No. 7 has negative MSF for all generators according to the direction of flow in that line. The proposed MSF allocates different levels of responsibility that related to the direction of the flow in transmission network. Table 2 compares the power flow computed using the GGDF and the proposed MSF applied to 5-bus test system with the results of load flow solution which based on NR method. The power flows computed with the proposed MSF are near to the power flows resulted from NR power flows for small changes in the generation outputs.

Tables 3-6 show comparison studies between the proposed MSF and the GGDF for two different emergency conditions. These emergency conditions are the outages of lines No. 2 and 6, respectively.

Table 3 shows a comparison between the GGDF and the proposed MSF applied on 5-bus test system when line 2 goes out. The proposed MSF reallocate the responsibilities of the individual generation in the power flow of transmission lines. The power flow in transmission line No. 1 is affected by $90 \%$ of $G_{1}$. While, the power flow components due to generations $G_{2}$ and $G_{5}$ are in the opposite direction $10.5 \%$ of $G_{2}$ and 10.8 of $G_{5}$. Lines No. 6 and 7 have negative MSF for all generators according to the new direction of the power flows in these lines. The proposed MSF reallocates the levels of responsibility that related to the direction of the flow in transmission network for the current emergency event.

Table 4 compares the power flow computed using the GGDF and the proposed MSF applied to 5-bus test system in the case of line 2 outage. The power flows computed with the proposed MSF are near to the power flows resulted from NR power flows for small changes in the generation outputs in this emergency condition.

Another emergency condition is considered to test the proposed MSF. In this condition, line No. 6 goes out of service. Table 5 compares the proposed MSF with the GGDF. Table 6 compares the power flow computed using the GGDF and that computed using the proposed MSF applied to 5-bus test system with the results of load flow solution which based on NR method. The power flows computed with the proposed MSF are near to the power flows resulted from NR power flows for small changes in the power generation outputs. Tables 1-6 show that the proposed MSF can be considered as alternative sensitivity factors to the GGDF factors.

TABLE 1 COMPASSION BETWEEN GGDF\& SUGGESTED MSF

\begin{tabular}{|c|c|c|c|c|c|c|}
\hline \multirow{2}{*}{$\begin{array}{c}\text { Line } \\
\text { No. }\end{array}$} & \multicolumn{3}{|c|}{ GGDF } & \multicolumn{3}{c|}{ Proposed MSF } \\
\cline { 2 - 7 } & $\mathrm{G}_{1}$ & $\mathrm{G}_{2}$ & $\mathrm{G}_{5}$ & $\mathrm{G}_{1}$ & $\mathrm{G}_{2}$ & $\mathrm{G}_{5}$ \\
\hline 1 & 0.6403 & -0.2061 & -0.1506 & 0.2058 & 0.1279 & 0.1535 \\
\hline 2 & 0.2660 & 0.1077 & 0.0500 & 0.1906 & 0.1185 & 0.1421 \\
\hline 3 & 0.1315 & 0.2026 & 0.1071 & 0.1736 & 0.1079 & 0.1295 \\
\hline 4 & 0.1553 & 0.2120 & 0.0910 & 0.1827 & 0.1136 & 0.1363 \\
\hline 5 & 0.3395 & 0.3673 & -0.3609 & 0.1537 & 0.0955 & 0.1147 \\
\hline 6 & 0.1435 & 0.0572 & -0.0957 & 0.0554 & 0.0344 & 0.0413 \\
\hline 7 & 0.0523 & 0.0237 & -0.2497 & -0.0614 & -0.0382 & -0.0458 \\
\hline
\end{tabular}


TABLE 2 COMPASSION OF LOAD FLOW SOLUTION FOR NORMAL OPERATION

\begin{tabular}{|c|c|c|c|}
\hline Line No. & NR Load flow & GGDF & $D_{\mathrm{m}}$ factors \\
\hline 1 & 15.956 & 20.667 & 15.919 \\
\hline 2 & 27.711 & 28.702 & 27.647 \\
\hline 3 & 29.514 & 29.257 & 29.446 \\
\hline 4 & 30.98 & 30.812 & 30.908 \\
\hline 5 & 33.369 & 33.485 & 33.292 \\
\hline 6 & 8.9514 & 9.4903 & 8.9307 \\
\hline 7 & -6.9425 & -6.7605 & -6.9264 \\
\hline
\end{tabular}

TABLE 3 COMPASSION BETWEEN GGDF\& SUGGESTED MSF FOR LINE 2 OUTAGE

\begin{tabular}{|c|c|c|c|c|c|c|}
\hline \multirow{2}{*}{ Line No. } & \multicolumn{3}{|c|}{$G G D F$ (D Coefficients) } & \multicolumn{3}{c|}{ Proposed D $D_{\mathrm{m}}$ factors } \\
\cline { 2 - 7 } & $\mathrm{G}_{1}$ & $\mathrm{G}_{2}$ & $\mathrm{G}_{5}$ & $\mathrm{G}_{1}$ & $\mathrm{G}_{2}$ & $\mathrm{G}_{5}$ \\
\hline 1 & 0.900 & -0.105 & -0.108 & 0.250 & 0.310 & 0.137 \\
\hline 2 & \multicolumn{6}{|c|}{ Outage } \\
\hline 3 & 0.251 & 0.250 & 0.128 & 0.222 & 0.275 & 0.122 \\
\hline 4 & 0.251 & 0.250 & 0.108 & 0.218 & 0.271 & 0.120 \\
\hline 5 & 0.385 & 0.384 & -0.355 & 0.234 & 0.291 & 0.129 \\
\hline 6 & 0.000 & -0.001 & -0.122 & -0.024 & -0.030 & -0.013 \\
\hline 7 & 0.000 & 0.000 & -0.263 & -0.051 & -0.064 & -0.028 \\
\hline
\end{tabular}

TABLE 4 COMPARISON TO LOAD FLOW SOLUTIONS FOR LINE 2 OUTAGE

\begin{tabular}{|c|c|c|c|}
\hline Line No. & NR Load flow & GGDF & $\mathrm{D}_{\mathrm{m}}$ factors \\
\hline 1 & 44.186 & 49.428 & 43.98 \\
\hline 2 & \multicolumn{3}{|c|}{ Outage } \\
\hline 3 & 42.048 & 42.113 & 41.852 \\
\hline 4 & 41.165 & 41.23 & 40.973 \\
\hline 5 & 38.978 & 39.076 & 38.796 \\
\hline 6 & -5.6016 & -5.6001 & -5.5755 \\
\hline 7 & -12.001 & -12.001 & -11.945 \\
\hline
\end{tabular}

TABLE 5 COMPASSION BETWEEN GGDF\& SUGGESTED MSF FOR LINE 6 OUTAGE

\begin{tabular}{|c|c|c|c|c|c|c|}
\hline \multirow{2}{*}{$\begin{array}{c}\text { Line } \\
\text { No. }\end{array}$} & \multicolumn{3}{|c|}{ GGDF (D Coefficients) } & \multicolumn{3}{c|}{ Proposed $D_{\mathrm{m}}$ factors } \\
\cline { 2 - 7 } & $\mathrm{G}_{1}$ & $\mathrm{G}_{2}$ & $\mathrm{G}_{5}$ & $\mathrm{G}_{1}$ & $\mathrm{G}_{2}$ & $\mathrm{G}_{5}$ \\
\hline 1 & 0.689 & -0.189 & -0.192 & 0.120 & 0.150 & 0.067 \\
\hline 2 & 0.210 & 0.084 & 0.084 & 0.126 & 0.157 & 0.070 \\
\hline 3 & 0.042 & 0.167 & 0.167 & 0.119 & 0.150 & 0.066 \\
\hline 4 & 0.250 & 0.249 & 0.026 & 0.200 & 0.251 & 0.111 \\
\hline 5 & 0.384 & 0.383 & -0.396 & 0.224 & 0.280 & 0.124 \\
\hline 6 & \multicolumn{6}{|c|}{ Outage } \\
\hline 7 & 0.000 & 0.001 & -0.222 & -0.042 & -0.053 & -0.024 \\
\hline
\end{tabular}

TABLE 6 COMPARISON TO LOAD FLOW SOLUTION FOR LINE 6 OUTAGE

\begin{tabular}{|c|c|c|c|}
\hline $\begin{array}{c}\text { Line } \\
\text { No. }\end{array}$ & $\begin{array}{c}\text { NR } \\
\text { Load flow }\end{array}$ & GGDF & D $_{\mathrm{m}}$ factors \\
\hline 1 & 19.693 & 24.622 & 19.649 \\
\hline 2 & 23.952 & 24.743 & 23.899 \\
\hline 3 & 23.738 & 23.143 & 23.685 \\
\hline 4 & 37.169 & 37.367 & 37.087 \\
\hline 5 & 36.724 & 37.029 & 36.643 \\
\hline 6 & \multicolumn{3}{|c|}{ Outage } \\
\hline 7 & -10.032 & -10.03 & -10.009 \\
\hline
\end{tabular}

To show the superiority of the proposed MSF, application examples based on the optimal generation dispatch of generation units are solved using the proposed MPSO.

Tables 7.A through 7.Cshow the effects of MPSO on the convergence and optimal dispatch solution of the generation costing model considering the MSF. In Table 7.A, the optimal dispatch results are presented based on the MPSO for the 5-bus test system at total generation output of 180 MW considering the both of GGDF and MSF factors. It is founded that, more economical solution is satisfied with the proposed MSF factors. The optimal generation costs are $372.12 \$ / \mathrm{hr}$ which is occurred when considering the MSF factors for computation of power flows in transmission lines. The use of GGDF leads to generation costs of $384.25 \$ / h r$. using the proposed MSF, more reserve levels are obtained from transmission network that can be used the effects of different congestion events. It is found that, the power flows in all transmission networks are located far from their bending limits of the transmission network.

Also, Table 7.B compares the results of the optimal power dispatch of generation companies considering the outage of line No. 6 while, the total power demand remains at $180 \mathrm{MW}$. The use of the proposed MSF leads to minimize the total generation costs $(379.98 \mathrm{\$} / \mathrm{hr})$ compared to the GGDF (387.98 \$/hr). The power flow constraints are kept within the congestion limits. It is found that the power flows in line No. 1 changes from 14.37 MW to 17.32 MW considering the MSF factors. The power flow in line $\mathrm{N}$ o. 1 considering the GGDF is changed from 37.39 MW to 37.39 MW. From these comparisons, more reserve levels from critical transmission network that connected between generation companies, (Line No. 1), are obtained at more economic solutions using the proposed MSF.

In Table 7.C, the proposed MPSO model is used to optimize the production costs for 57-bus test system. The use of the proposed MSF leads to the minimum the total generation costs from $(65056.0 \mathrm{\$} / \mathrm{hr})$ to 
$(63207 \$ / \mathrm{hr})$ using the GGDF. Added to the economic solution, the power flow constraints are satisfied. Congestion constraints are considered for transmission network. No violation was found in any line of the transmission circuit.

The advantages of the proposed MSF are:

- The proposed MSF is simple to implement

- The proposed MSF is based on the actual system measurements

- The proposed MSF doesn't need any approximation in voltage/circuit resistance.

- The proposed MSF is very effective for obtaining more economic solutions.

- The proposed MSF is suitable for on-line operation because it is sensitive to small changes in power generation outputs.

- In terms of the deregulated environment of electrical power systems, the use of the proposed MSF helps the ISO to allocate the responsibility of different network users in a new fashion.

Figure 1 shows comparison between computation times for the studied cases. The use of the proposed MSF reduces the computation times compared to the use of GGDF. Also, the MPSO version is successively applied to solve the optimal power dispatch problem to obtain economic solutions considering the proposed sensitivity factors. At the same time, it is provide a guarantee of the power flows in the transmission circuits within their maximum limits.

TABLE 7 RESULTS OF GENERATION DISPATCH USING MPSO VERSION

A. five-bus system $\left(\left(\sum P G=180 M W\right)\right.$

\begin{tabular}{|c|c|c|c|}
\hline Variables & $\begin{array}{c}\text { Max. } \\
\text { limits }\end{array}$ & BPSO & MPSO \\
\hline$P G_{1}(\mathrm{MW})$ & 120 & 89.655 & 113.09 \\
\hline$P G_{2}(\mathrm{MW})$ & 90 & 61.828 & 64.41 \\
\hline$P G_{5}(\mathrm{MW})$ & 60 & 36.017 & 10.00 \\
\hline$P F_{1}(\mathrm{MW})$ & 40 & 37.69 & 14.37 \\
\hline$P F_{2}(\mathrm{MW})$ & 32 & 31.762 & 27.40 \\
\hline$P F_{3}(\mathrm{MW})$ & 30 & 27.678 & 29.62 \\
\hline$P F_{4}(\mathrm{MW})$ & 45 & 29.763 & 31.25 \\
\hline$P F_{5}(\mathrm{MW})$ & 45 & 39.54 & 38.72 \\
\hline$P F_{6}$ (MW) & 40 & 12.624 & 9.90 \\
\hline$P F_{7}$ (MW) & 12 & -3.075 & -4.60 \\
\hline \multicolumn{2}{|c|}{ Gen. costs $\$ / \mathrm{hr}$} & 384.25 & 372.12 \\
\hline
\end{tabular}

B. five-bus system $\left(\sum P G=180 M W\right)$, Line 6 Outage

\begin{tabular}{|c|c|c|c|}
\hline Variables & $\begin{array}{l}\text { Max. } \\
\text { Limits }\end{array}$ & BPSO & MPSO \\
\hline$P G_{1}(\mathrm{MW})$ & 120 & 83.52 & 94.65 \\
\hline$P G_{2}(\mathrm{MW})$ & 90 & 62.05 & 56.04 \\
\hline$P G_{5}(\mathrm{MW})$ & 60 & 41.94 & 36.81 \\
\hline$P F_{1}(\mathrm{MW})$ & 40 & 37.44 & 17.32 \\
\hline$P F_{2}(\mathrm{MW})$ & 32 & 25.83 & 21.77 \\
\hline$P F_{3}(\mathrm{MW})$ & 30 & 20.37 & 21.75 \\
\hline$P F_{4}(\mathrm{MW})$ & 45 & 37.07 & 35.62 \\
\hline$P F_{5}(\mathrm{MW})$ & 45 & 39.54 & 39.71 \\
\hline$P F_{6}(\mathrm{MW})$ & 40 & \multicolumn{2}{|c|}{ Outage } \\
\hline$P F_{7}(\mathrm{MW})$ & 12 & -8.73 & -7.51 \\
\hline Gen. cost & $\$ / \mathrm{hr}$ & 387.98 & 379.98 \\
\hline
\end{tabular}

C. IEEE 57-bus system $\left(\sum P G=1630.8 M W\right)$

\begin{tabular}{|c|c|c|c|c|c|}
\hline \multirow{2}{*}{ Variables } & \multirow{2}{*}{ Max limits } & \multicolumn{2}{|c|}{ BPSO } & \multicolumn{2}{c|}{ MPSO } \\
\cline { 3 - 6 } & & GGDF & MSF & GGDF & MSF \\
\hline$P G_{1}(\mathrm{MW})$ & 350 & 299.72 & 154.08 & 334.79 & 81.87 \\
\hline$P G_{2}(\mathrm{MW})$ & 200 & 146.36 & 156.29 & 119.71 & 129.79 \\
\hline$P G_{5}(\mathrm{MW})$ & 300 & 186.36 & 196.29 & 159.71 & 169.79 \\
\hline$P G_{8}(\mathrm{MW})$ & 200 & 146.36 & 156.29 & 119.71 & 129.79 \\
\hline$P G_{9}(\mathrm{MW})$ & 450 & 295.66 & 401.54 & 367.15 & 579.79 \\
\hline$P G_{11}(\mathrm{MW})$ & 200 & 146.36 & 156.29 & 119.71 & 129.79 \\
\hline$P G_{13}(\mathrm{MW})$ & 410 & 410 & 410 & 410 & 410 \\
\hline$P F_{1}(\mathrm{MW})$ & 350 & 311.67 & 254.89 & 343.43 & 250.19 \\
\hline$P F_{2}(\mathrm{MW})$ & 250 & -106.84 & -153.66 & -101.79 & -184.96 \\
\hline$P F_{3}(\mathrm{MW})$ & 60 & 44.25 & -1.98 & 39.42 & -45.59 \\
\hline$P F_{4}(\mathrm{MW})$ & 150 & -104.07 & -125.69 & -101.06 & -139.24 \\
\hline$P F_{78}(\mathrm{MW})$ & 75 & -11.05 & -12.50 & -11.56 & -14.33 \\
\hline$P F_{79}(\mathrm{MW})$ & 50 & -2.85 & -2.69 & -2.96 & -2.72 \\
\hline$P F_{80}(\mathrm{MW})$ & 100 & -27.14 & -34.42 & -28.21 & -41.69 \\
\hline \multicolumn{2}{|c|}{ Gen. Cost $\$ / h r$} & 65056 & 63207 & 63720 & 61528 \\
\hline
\end{tabular}

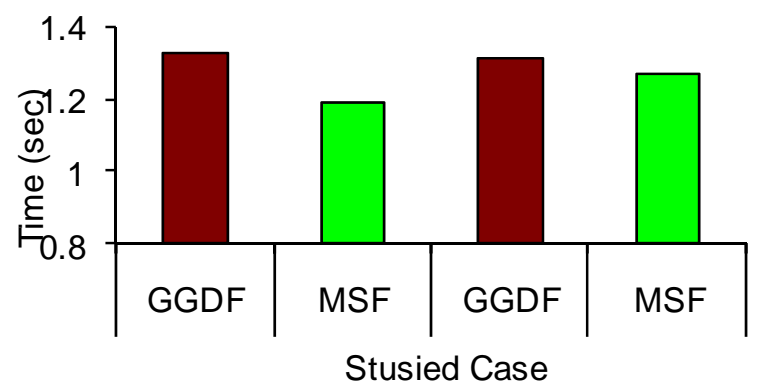

Fig. 1 Computation time for different studied cases of 57-bus test system 


\section{Conclusion}

This paper proposes accurate sensitivity factors to compute the power flows in transmission lines in terms of power generation outputs. The main advantages of the proposed sensitivity factors are their simplicity, dependency on the actual measurements of power flow and generation outputs, independent on the slack bus selection and these sensitivity factors do not depend on any approximation in the bus voltages or lines resistance. The use of the proposed MSF reduces the computation times compared to the use of GGDF. Added to that, a modified PSO version which deals with the typical production cost minimization in the electrical power markets is proposed. The MPSO version reduces experience terms to single compact term. Comparison studies which are based on the proposed sensitivity factors and the MPSO version of have been performed compared to the conventional version.

Some of the opportunities for future work based on the proposed procedures in this paper are: the generalization of these methodologies for electricity market problems to maximize the social benefits and obtaining an optimal procedure for transmission recovery problems such as transmission loss allocation, congestion cost allocation and wheeling cost allocation.

\section{References}

[1] W. Y. Ng, Generalized Generation Distribution Factors for Power System Security Evaluation, IEEE Trans. on Power Apparatus and Syst., PAS-100, 1981, pp. 1001-1005.

[2] J. Bialek, Topological Generation and Load Distribution Factors for Supplement Charge Allocation in Transmission Open Access, IEEE Trans. on Power Syst. , Vol. 12, No. 3, 2005, pp. 1185-1193.

[3] M. Pantoš et al., Modified Topological Generation and Load Distribution Factors, IEEE Trans. on Power Syst, Vol. 20, No. 4, 2005, pp. 1998-2005.

[4] F. Milano, C. A. Canizares, and M. Invernizzi, Multiobjective Optimization for Pricing System Security in Electricity Markets, IEEE Trans. on Power Syst., Vol. 18, No. 2, May 2003, pp. 596-604.

[5] H. Yamin, S. Al-Agtash, and $M$. Shahidehpour, Security-Constrained Optimal Generation Scheduling for GENCOs, IEEE Trans. on Power Syst. Vol. 19, No. 3, 2004, pp. 1365-1372.
[6] C. Batlle and J. Barquin, A Strategic Production Costing Model for Electricity Market Price Analysis, IEEE Trans. on Power Syst., Vol. 20, No. 1, 2005, pp. 67-74.

[7] P. Sánchez-Martín, A. Ramos, J. F. Alonso, Probabilistic Midterm Transmission Planning in Liberalized Market, IEEE Trans. on Power Syst., Vol. 20, No. 4, 2005, pp. 2135-2142.

[8] Zwe-Lee Gaing, Particle Swarm Optimization to Solving the Economic Dispatch Considering the Generator Constraints, IEEE Trans. on Power Syst., Vol. 18, No. 3, 2003, pp. 1187-1195.

[9] Jong-Bae Park, Ki-Song Lee, Joong-Rin Shin, and K. Y. Lee, A Particle Swarm Optimization for Economic Dispatch with Nonsmooth Cost Functions, IEEE Trans. on Power Syst. , Vol. 20, No. 1, 2005, pp. 34-42.

[10] H. H. Balci, J. F. Valenzuela, Scheduling Electric Power Generators Using Particle Swarm Optimization Combined with the Lagrangian Relaxation Method, Int. J. Appl. Math. Compu. Sci., Vol. 14, No. 3, 2004, pp. 411-421.

[11] H. Yoshida, K. Kawata, Y. Fukuyama, S. Takayama and Y. Nakanishi, "A Particle Swarm Optimization for Reactive Power and Voltage Control Considering Voltage Security Assessment, IEEE Trans. on Power Syst., Vol. 15, No. 4, 2005, pp. 1232-1239.

[12] I. Musirin, M.R. Kalil, M. M. Othman, Optimal Reactive Power Dispatch using Ant Colony Optimization Technique, WSEAS Transactions on Power Systems, Vol. 1, Issue 8, 2006, pp. 1423-1430.

[13] Cheng-Chien Kuo, Po-Hung Chen, ChunLiang Hsu, Shieh-Shing Lin, Particle Swarm Optimization for Capacitor Allocation and Dispatching Problem Using Interactive BestCompromise Approach, WSEAS Transactions on Systems, Vol. 4, Issue 9, 2005, pp. 15631572.

[14] M. A. Abido, Optimal Design of Power System Stabilizers using Particle Swarm Optimization, IEEE Trans. on Energy Conversion, Vol. 17, No. 3, 2002, pp. 406413.

[15] M. A. Abido, Optimal Power Flow using Particle Swarm Optimization, International Journal of Electrical Power and Energy Syst., Vol. 24, No. 7, 2002, pp. 563-571.

[16] S. Naka, T., T. Yura, and Y. Fukuyama, A Hybrid Particle Swarm Optimization for Distribution State Estimation, IEEE Trans. on Power Syst., Vol. 18, No. 1, 2003, pp. 60-68. 
[17] T. O. Ting, M. V. C. Rao, and C. K. Loo, A Novel Approach for Unit Commitment Problem via Effective Hybrid Particle Swarm Optimization for Distribution State Estimation, IEEE Trans. on Power Syst., Vol. 21, No. 1, 2005, pp. 411-418.

[18] C. Rani, M. Rajesh Kumar, K. Pavan, Multiobjective Generation Dispatch using Particle Swarm Optimisation with Multiple Fuel Option, WSEAS Transactions on Power Systems, Vol. 1, Issue 10, 2006, pp. 18191823.

[19] Hongwen Yan, Rui Ma, A Multiobjective Particle Swarm Optimization Approach and Application in Multiobjective Electricity Power Dispatch, WSEAS Transactions on Information Science \& Applications, Vol. 3 Issue 7, 2006, pp. 1288-1293.

[20] Stella Morris, P. K. Dash, Ezra Morris, PSObased Optimal Design of a Neuro-sliding Mode Controller for the Transient Stability Enhancement of Multimachine Power Systems with UPFC, WSEAS Transactions on Power Systems, Vol. 1 Issue 10, 2006, pp. 1667-1674.

[21] A. A. Abou El-Ela, and R. El-Sehiemy, Different Transmission Loss Allocation in Deregulated Power Markets, the proceeding $42^{\text {nd }}$ International Universities Power Engineering Conference (UPEC 2007), 4-6 September 2007, Brighton, England, pp. 634640.

[22] A. A. Abou El-Ela, M. Bishr, S. Allam and R. El-Sehiemy, Optimal Preventive Control Actions in Power System Using MultiObjective Fuzzy Linear Programming Technique, Journal of Electric Power Systems Research, Vol. 74, No. 1, 2005, pp. 147-155

[23] R. D. Zimmerman, et al., MATPOWER Version 3.0, a MATLAB ${ }^{\text {TM }}$ Power System Simulation Package, 2005, [online]. Available: www.pserc.cornell.edu/matpower.

\section{APPENDIX}

The five-bus test system (Fig. A.1). All buses data in terms of generation/demand are reported in Table A.1. The data of transmission lines in the system have the values of series resistances and reactance's and the shunt admittance as reported in Table A.2. The 5-bus test system has three generators at buses 1, 2 and 5 . The base $\mathrm{KV}=400 \mathrm{KV}$, The base MVA equals 100.

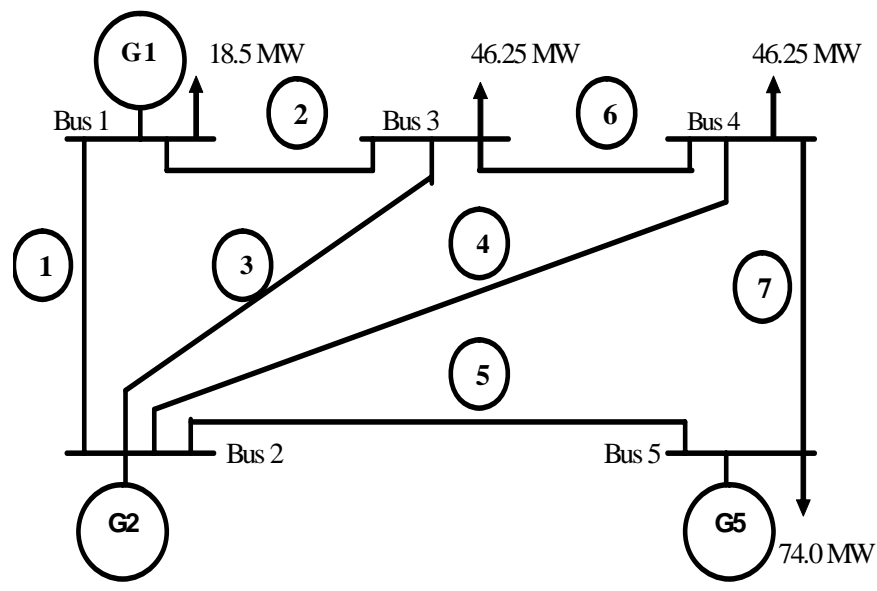

Fig. A.1 The line Diagram for the 5-bus test system

Table A.1 Five-bus transmission line data

\begin{tabular}{|c|c|c|c|c|c|}
\hline \multirow{2}{*}{$\begin{array}{c}\text { Line } \\
\text { No. }\end{array}$} & \multicolumn{2}{|c|}{ Bus } & \multirow{2}{*}{$\begin{array}{c}\text { Impedance } \\
Z\end{array}$} & $\begin{array}{c}\text { Line } \\
\text { Charge } \\
\text { Y/2 }\end{array}$ & $\begin{array}{c}\text { Line } \\
\text { Admittance }\end{array}$ \\
\hline 1 & 1 & 2 & $0.02+\mathrm{j} 0.06$ & $\mathrm{j} 0.030$ & $5.00-\mathrm{j} 15.0$ \\
\hline 2 & 1 & 3 & $0.08+\mathrm{j} 0.24$ & $\mathrm{j} 0.025$ & $1.25-\mathrm{j} 3.75$ \\
\hline 3 & 2 & 3 & $0.06+\mathrm{j} 0.18$ & $\mathrm{j} 0.020$ & $1.67-\mathrm{j} 5.00$ \\
\hline 4 & 4 & 2 & $0.06+\mathrm{j} 0.18$ & $\mathrm{j} 0.020$ & $1.67-\mathrm{j} 5.00$ \\
\hline 5 & 2 & 5 & $0.04+\mathrm{j} 0.12$ & $\mathrm{j} 0.015$ & $2.50-\mathrm{j} 7.50$ \\
\hline 6 & 3 & 4 & $0.01+\mathrm{j} 0.03$ & $\mathrm{j} 0.010$ & $10.0-\mathrm{j} 30.0$ \\
\hline 7 & 4 & 5 & $0.08+\mathrm{j} 0.24$ & $\mathrm{j} 0.025$ & $1.25-\mathrm{j} 3.75$ \\
\hline
\end{tabular}

Table A.2 Five-bus test system bus data

\begin{tabular}{|c|c|c|c|c|}
\hline $\begin{array}{c}\text { Bus } \\
\text { No. }\end{array}$ & $\begin{array}{c}\text { PG }^{\text {max }} \\
\text { MW }\end{array}$ & $\begin{array}{c}\text { PG }^{\text {min }} \\
\text { MW }\end{array}$ & $\begin{array}{c}\text { PG }_{0} \\
\text { MW }\end{array}$ & $\begin{array}{c}\text { Load } \\
\text { MW }\end{array}$ \\
\hline 1 & 120 & 10 & 90.44 & 18.5 \\
\hline 2 & 90 & 10 & 60 & 0 \\
\hline 3 & 0 & 0 & 0 & 46.25 \\
\hline 4 & 0 & 0 & 0 & 46.25 \\
\hline 5 & 60 & 10 & 40 & 74.0 \\
\hline
\end{tabular}

